ARCHIVO ESPAÑOL DE ARTE, XCIII, 372

OCTUBRE-DICIEMBRE 2020, pp. 409-416

ISSN: 0004-0428, eISSN: 1988-8511

https://doi.org/10.3989/aearte.2020.27

\title{
VARIA
}

\section{FRANCISCO PACHECO Y UNA ANUNCIADA INTERVENCIÓN DE FERNANDO III EL SANTO: UN TESTIMONIO SOBRE EL LIBRO DE RETRATOS*}

\author{
ADAM JASIENSKI ${ }^{1}$ \\ Southern Methodist University
}

\begin{abstract}
Se da a conocer un testimonio de Francisco Pacheco sobre su Libro de retratos, que permite comprobar algunas hipótesis acerca de este manuscrito, conectadas con su materialidad, valor y biografía, y que se analiza en relación con el tema literario del manuscrito encontrado.

Palabras clave: Francisco Pacheco; Libro de retratos; San Fernando; Juan Martínez Montañés; Juana Pacheco; Diego Velázquez; Sevilla; El manuscrito encontrado (tema literario).
\end{abstract}

\section{SAINT FERDINAND III'S INTERCESSION ON BEHALF OF FRANCISCO PACHECO: A TESTIMONY CONCERNING THE BOOK OF PORTRAITS}

This article introduces a testimony by Francisco Pacheco concerning his Book of Portraits, which confirms certain hypotheses about the manuscript, including its form, value, and biography. The account is then examined via the literary topos of the found manuscript.

Key words: Francisco Pacheco; The Book of Portraits; Saint Ferdinand; Juan Martínez Montañés; Juana Pacheco; Diego Velázquez; Seville; The found manuscript (literary topos).

Cómo citar este artículo / Citation: Jasienski, Adam (2020): "Francisco Pacheco y una anunciada intervención de Fernando III el santo: Un testimonio sobre el Libro de retratos". En: Archivo Español de Arte, vol. 93, núm. 372, Madrid, pp. 409-416. https://doi.org/10.3989/aearte.2020.27

La iniciativa de los habitantes de Sevilla por promover el largo proceso hacia la deseada canonización del rey Fernando III ha recibido extensa atención. Pintores como Bartolomé Esteban Murillo participaron en la descripción y evaluación de la fecha de elaboración de pinturas y

\footnotetext{
* Agradezco profundamente a César Manrique Figueroa, Juan Luis González García, María Lumbreras y Peter Skow, así como a los dos evaluadores anónimos de este artículo, y el apoyo institucional del Center for Advanced Study in the Visual Arts de la National Gallery of Art, y de la Facultad de Historia del Arte y del University Research Council de la Southern Methodist University. El presente trabajo desarolla temas examinados de manera parcial en mi tesis doctoral (sin publicar), donde se presenta por primera vez el entonces inédito testimonio de Pacheco: Adam Jasienski (2016). In the Guise of Holiness: Sanctity and Portraiture in the Early Modern Hispanic World. Tesis doctoral. Cambridge: Harvard University: 308-314

1 ajasienski@smu.edu / ORCID iD: https://orcid.org/0000-0002-9135-3885
} 
esculturas relacionadas con el rey santo, con el fin de demostrar así la presencia de un culto antiguo en la ciudad y abrir una vía hacia una canonización per viam cultus, además de escribir un capítulo temprano en la aplicación práctica de la historia del arte, antes de su formación como disciplina académica en los siglos subsiguientes ${ }^{2}$. Sin embargo, un episodio importante relacionado con el culto a san Fernando ha sido ignorado por investigadores del tema hasta ahora, siendo de interés tanto por los personajes involucrados - también artistas - como por su valor para clarificar la historia de vida de una de las obras maestras del siglo de oro español, el Libro de retratos de Francisco Pacheco ${ }^{3}$.

No se sabe gran cosa sobre la biografía temprana del Libro como objeto físico (Marta Cacho Casal la llamó "nebulosa"4, mientras que Bonaventura Bassegoda escribió que "sorprende que...

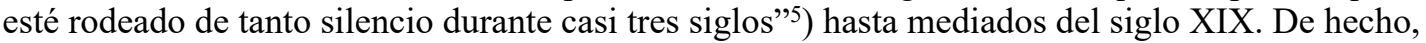
la senda del manuscrito se pierde poco después de la muerte de Pacheco y, tras varias reapariciones más o menos apócrifas, solo readquiere un paradero cierto a partir de 1864, formando hoy parte del acervo de la Biblioteca del Museo Lázaro Galdiano ${ }^{6}$. Pero entre septiembre y octubre del año de 1627, es decir mientras todavía vivía su autor, el famoso manuscrito desapareció por primera vez y después volvió a aparecer en un episodio que, según se desprende del parecer del mismo Pacheco era entonces extensamente comentado.

Conforme a un documento conservado en el Archivio Segreto Vaticano, Pacheco compareció ante los notarios del Cabildo catedralicio sevillano el 19 de enero de 1628 como uno de los testigos llamados a dar testimonio en la fase preparatoria de la causa de la elevación a los altares del rey Fernando III, que el Cabildo quería presentar ante el pontífice en Roma. Como veedor de pinturas para el Santo Oficio Pacheco fue llamado para examinar varias imágenes relacionadas con el santo rey, para confirmar su antigüedad y culto ${ }^{7}$. A continuación el pintor y teórico de arte sanluqueño ofreció un testimonio de un milagro sucedido a él mismo, declarando que "sabe y oye dezir no cesa nuestro señor de honrrar a este su siervo [Fernando III] con ottros muchos admirables casos en varias, y diversas materias como en salud, y enfermos desafuciados pero con mucha mas frequencia y opinion en materia de hallar cossas perdidas, o hurtadas" y empezó a contar la historia de los eventos que se desarrollaron a partir del 7 de septiembre de 1627. Pacheco afirma "que teniendo un libro de retratos de Varones ynsignes que era trabaxo suyo de mas de treynta años, y que lo estimava en mill ducados, el qual libro se lo hurtaron con otros muchos papeles y libros de la misma curiossidad, y facultad". Con el libro desaparecido y con su autor tan desesperado "por una tan gran perdida", un amigo "le aconsexo mandase luego dezir una missa al sancto Rey", lo que Pacheco hizo, pagando una limosna para que se celebrara una misa al sepulcro de san Fernando en la Catedral de Sevilla ${ }^{8}$. Del testimonio de Juan Martínez Montañés, que sigue al de Pacheco, resulta que es el escultor mismo quien se lo recomendó al pintor, notando que Pacheco, "aviendo hecho muchas diligencias humanas para buscarle, y hecho dezir algunas misas a las animas de purgatorio segun dixo a este testigo, y con la devocion $\mathrm{q}[\ldots]$ tiene al dho $\mathrm{s}^{\text {to }}$ rey don fer ${ }^{\text {do }}$ le dixo, $q$ le hiciese dezir una missa encomendandose, $q$ Pareciese el dho libro"9. Felizmente, pasado menos de un mes, el Libro volvió a aparecer.

El 4 de octubre del mismo año de 1627 "fue el mismo mozo q lo avia hurtado llevarselo a vender y poner en las manos a una hija de este testigo que estava y esta en Madrid que se llama

2 Quiles, 1999: 203-49. Wunder, 2001: 670-675.

3 Para una recopilación de la extensa bibliografía sobre el Libro de retratos hasta 2011 ver Cacho Casal, 2011. Bassegoda, 2012: 180. Las recientes aportaciones al tema son Meissen, 2019: 32-54. Bassegoda, 2018: 281-317. Navarrete Prieto, 2016: 77-84.

4 Cacho Casal, 2011: 124.

5 Bassegoda, 2012: 178.

6 Cacho Casal, 2011: 124-28.

7 En esta caussa [...] pressento por testigo al señor Fran. ${ }^{c o}$ Pacheco, 19 de enero de 1628, Archivio Segreto Vaticano, Roma (ASV), Congregazione dei Riti (Congr. Riti), Processus 1098, f. 52 verso. El documento tiene dos paginaciones que no corresponden entre sí. Aquí utilizo la paginación que aparece en la esquina superior exterior de la página.

8 Todas las citas de este párrafo proceden de ASV, Congr. Riti, Processus 1098, f. 53 r.

9 ASV, Congr. Riti, Processus 1098, f. 162 v. 
Doña Juana Pacheco casada con Dg. ${ }^{\circ}$ Velasquez pintor y ugier de camara de su mag. ${ }^{\text {d". No es de }}$ sorprender que la hija de Pacheco y su marido inmediatamente "reconocieron ser prenda de su Padre, con lo qual lo aseguraron, y le dieron aviso del hallazgo". Pacheco encargó una misa de agradecimiento al rey santo y otra a la Virgen, incluso "antes de aver venido a su mano" el Libro, que le llegó "dentro de otro tiempo". Lo particularmente milagroso de este hallazgo, según Pacheco - y tal vez lo más interesante desde nuestro punto de vista - es que, "aviendo sido el libro de quadernos sueltos, y de retratos y dibuxos sueltos que se pudieran cada uno de por si vender vino todo entero sin faltar una hoja tan sola, y sin averse maltratado". Aunque los demás papeles que perdió en el mismo robo no se encontraron, "no hizo casso, ni sintio la perdida" ya que "lo demas no lo estimava sino solamente este libro, y assi solamente le vino el libro por el qual solo avia hecho su particular devoción...”. Pacheco termina su relación de este episodio asegurándoles a sus oyentes (los notarios y miembros del Cabildo catedralicio de Sevilla) y lectores (supuestamente varios cardenales y otros funcionarios de la Sagrada Congregación de Ritos en Roma) que el hecho tenía ya amplia fama, aunque habían pasado tan solo tres meses desde que ocurrió, ya que "tuvieron muchos otros assi de esta ciudad como fuera de ella, particular noticia de este milagroso succeso, y dadole el parabien de ello, como de cossa de tanta estima, y de que en españa avia tanta noticia"10.

\section{Las enseñanzas del testimonio de Pacheco}

Aunque Pacheco ya lo designara como un libro en el interrogatorio de 1628, al igual que en su testamento de más de una década más tarde de $1639^{11}$, queda claro que Bonaventura Bassegoda supone correctamente que "durante muchos años de la vida de su autor este proyecto de libro no fuera más allá de una simple carpeta en donde se conservaban los retratos y los borradores de las biografías"12. Describiendo el Libro como un "libro de quadernos sueltos, y de retratos y dibuxos sueltos que se pudieran cada uno de por si vender", Pacheco revela que era un libro tan solo teóricamente, porque en la práctica era más bien un cartapacio de hojas sueltas sin encuadernar, lo que permitía a su autor la reorganización del mismo mientras cambiaba su conceptualización durante los años. Probablemente no eran tan solo dibujos que lo integraban, sino también textos ("quadernos sueltos"), con toda probabilidad borradores de los elogios y rótulos que después acompañarían algunos de los retratos. En algún momento después de $1628 \mathrm{y}$, como sugiere Bassegoda, después de 1639, ya que esta es la última fecha mencionada en el Libro, Pacheco tomó la decisión de organizar y numerar una selección final de dibujos, aunque esta versión también quedaría sin terminar al momento de su muerte en $1644^{13}$.

Pero también es posible que, aún después de 1639, el Libro hubiera quedado sin encuadernar, compuesto de hojas sueltas y dibujos posiblemente numerados, pero no agrupados, es decir, en el estado en que se encontraba en el momento de su robo en 1627. Esto correspondería con la interpretación de Cacho Casal, quien declara que "no resulta sencillo establecer cuándo fue dividido el Libro y en qué circunstancias. [...] Se puede concluir que cuando su autor murió la obra pasó a formar parte del mercado de arte y dejó de percibirse como una unidad [...]"14. Si el Libro fuera a la muerte de Pacheco todavía una colección de dibujos "que se pudieran cada uno de por si vender", esto no tan solo corroboraría el argumento de Cacho Casal, quien supone que "el autor no se encargó de encuadernarlo, o que, si lo hizo, alguien metió luego mano en el Libro y alteró su orden" "15, pero también explicaría por qué faltan dos dibujos según la numeración del manuscrito que hoy se encuentra en la Biblioteca Lázaro Galdiano ${ }^{16}$.

\footnotetext{
10 Todas las citas de este párrafo proceden de ASV, Congr. Riti, Processus 1098, f. 53 r.

11 Salazar, 1928: 159.

12 Bassegoda, 2000-2001: 208.

13 Bassegoda, 2000-2001: 208.

14 Cacho Casal, 2011: 135.

15 Cacho Casal, 2011: 139.

${ }^{16}$ Bassegoda i Hugas, 1991: 188. Bassegoda, 2000-2001: 208. Ver también Navarrete Prieto, 2016: 83.
} 
Es fácil de imaginar que el Libro de retratos era para Pacheco, invaluable, siendo un trabajo de casi la mitad de su vida y — en el momento de su desaparición — aún lejos de estar terminado. No obstante, lo estimó en mil ducados, probablemente para comunicar sin ambigüedad ninguna su gran valor a los evaluadores de la documentación fernandina, llamándolo "un libro de retratos de Varones ynsignes que era trabaxo suyo de mas de treynta años, y que lo estimava en mill ducados". Lo confirmó Martínez Montañés, que lo describió como "un libro de retratos de dibujos de personas insignes, y varones ylustres de todo genero, de cosas q tenia hecho, y oy le va continuando, q valia en el estado q se lo hurtaron mill ducados" 17 o, es de suponer, que aún estando incompleto e inacabado valía esta considerable cantidad de dinero. Siguiendo esta línea, ¿qué representaban para Pacheco mil ducados en 1628? Con base en los trabajos y pagos anteriores del mismo Pacheco, sabemos que recibió, por ejemplo, cincuenta ducados por un retrato del conde duque de Olivares en marzo de $1610^{18}$ y que en 1604 había cobrado al duque de Alcalá mil ducados —entonces el mismo valor que calcularía para su Libro unos veinticuatro años más tarde- por el enorme complejo de pinturas para el techo de la Casa de Pilatos ${ }^{19}$.

Pero quizás es más esclarecedor el contrato que Francisco de Zurbarán —un pintor todavía joven pero ya en demanda - firmaría en ese mismo año de 1628 con los mercedarios de Sevilla por una serie de veintidós telas grandes con escenas de la vida del fundador de la orden, san Pedro Nolasco. Los frailes se obligaron a pagarle al pintor extremeño mil quinientos ducados divididos en tres pagas: al principio del trabajo, después de terminados once cuadros y el resto cuando estuviera terminada la serie ${ }^{20}$. De estos fondos el pintor seguramente tuvo que mantener, en las palabras de José Fernández López, "un importante taller o [...] un buen número de colaboradores" 21 . Es decir, Pacheco estimaba el valor de su Libro de retratos en dos tercios de lo que un artista entonces en boga y su equipo de artistas y artesanos cobraban por la creación de veintidós cuadros grandes, multifigurales e iconográficamente complejos.

El testimonio de Pacheco, nacido en 1564, nos ofrece también una fecha aproximada para los primeros retratos del Libro: si la cifra de "mas de treynta años" que menciona Pacheco en 1628 es correcta, esto arrojaría la segunda mitad de la década de 1590, entonces cuando el pintor ya era un artista bien establecido en la ciudad de Sevilla. Cacho Casal sugiere que Pacheco empezó a trabajar en el Libro hacia 1587, a los veintitrés años, es decir, más de cuarenta años antes de su declaración en el proceso de san Fernando. Es posible que, desde la perspectiva de sus sesenta y tres años, Pacheco había olvidado cuándo precisamente empezó ese proyecto de larga duración. Igualmente, existe la posibilidad de que el retrato del padre jesuita Rodrigo Álvarez (que Cacho Casal considera como el más temprano del Libro, al vincularlo con un poema funerario escrito en 1587, la fecha de muerte de Álvarez) no fuera el mismo que Pacheco declaró en su Arte de la pintura haber pintado mientras el jesuita todavía vivía ${ }^{22}$.

Por último, el testimonio confirma la estrechez de los lazos que mantuvo Pacheco con Juan Martínez Montañés. No sorprende que Martínez Montañés haya socorrido a Pacheco con su consejo, y que mencionara el prodigio concedido a Pacheco en su propio testimonio. Al parecer los dos artistas le habían dado pronto la espalda a su famosa riña de 1622 sobre la división laboral entre pintores y escultores, ya que en 1624-1625 habían colaborado en la ejecución de la escultura de Francisco de Borja ${ }^{23}$. Es más, al mes siguiente de su testimonio en 1628 Martínez Montañés firmaría el contrato para la escultura de la Inmaculada de la Catedral de Sevilla, para cuyas encarnaciones no contrataría a nadie más que a Pacheco ${ }^{24}$.

\footnotetext{
17 ASV, Congr. Riti, Processus, 1098, f. 162 v.

${ }_{18}$ Cacho Casal, 2011: 70 n. 51.

19 Cacho Casal, 2011: 88.

20 Fernández López, 2002: 267.

${ }^{21}$ Fernández López, 2002: 268.

22 Cacho Casal, 2011: 179-80.

23 González Gómez, 1995: 47.

24 Gámez Martín, 2005: 989-90.
} 


\section{El manuscrito descubierto}

Quizás lo más notable del testimonio de Pacheco es que la historia que cuenta es, ni más ni menos, una versión del tema literario del "manuscrito descubierto" o "redescubierto" 25 . Este topos aparece con frecuencia en la producción literaria de la época. Por ejemplo, en los Diálogos de fray Heitor Pinto (O.S.H.) de 1576, uno de los protagonistas describe su pasión por la literatura epistolar, pidiendo que un amigo le prestara "vn quaderno [...] dō[n]de auia muchos originales de cartas familiares en nuestra lengua Portuguesa, que me dixo que se lo auia vē[n]dido por bien poco dinero vn moço en Madrid, donde dezia auerle hallado, que parece que algun Portugues lo trahia y lo perdio o se lo tomaron..."26. Quizás el ejemplo mejor conocido del "manuscrito descubierto", además de más cercano al milagro descrito por Pacheco, viene de Don Quijote. Según la narración de Cervantes, explicando el origen de la segunda parte del libro, leemos que "llegó un muchacho a vender unos cartapacios y papeles viejos a un sedero; y como yo soy aficionado a leer, aunque sean los papeles rotos de las calles, llevado desta mi natural inclinación, tomé un cartapacio de los que el muchacho vendía, y vile con carácteres que conocí ser arábigos" 27 . El narrador, con la ayuda de un traductor, se dio cuenta de que lo que acababa de encontrar era la siguiente parte de las aventuras del caballero manchego.

El paralelismo entre el milagro del Libro de retratos — con el hurto del objeto, su traslado de un lado a otro, un mozo imprudente, el mayor valor del objeto de lo pensado y la suerte de caer en las manos de la persona más adecuada para cuidarlo- y las anécdotas citadas por Pinto y Cervantes, sugiere fuertemente que Pacheco estuviera basando su testimonio en la narrativa en vez de hechos reales. La historiadora Natalie Zemon Davis, en su investigación de los aspectos literarios de las cartas de remision en la Francia del siglo XVI, observa que "[...] el artificio de la ficción no concedía necesariamente falsedad a un relato; bien podía otorgarle verosimilitud o una verdad moral"28. En el testimonio de Pacheco también notamos las "posibles tramas [...] aprendidas en previos momentos de escuchar y contar historias" que Zemon Davis identifica en las declaraciones de sus protagonistas que, al igual que en el caso de Pacheco, eran transmitidas por vía oral y "traducidas" por notarios, con resultados más o menos codificados ${ }^{29}$. Pacheco combina un objeto indudablemente real con un hecho posible pero imposible de comprobar, vistiéndolos en el lenguaje de una forma literaria relacionada con lo que François Delpech designó como "un modelo imaginario ya fuertemente arraigado en las representaciones colectivas de la España de fines del siglo XVI" ${ }^{30}$. Esta combinación le otorga un valor documental adicional al testimonio de Pacheco, confirmando que el milagro de san Fernando no era un "unicum", sino que se enraizaba fuertemente dentro de una tradición confirmada por su recurrencia en una multitud de fuentes.

En conclusión, retomo las palabras con las que, en 1941, Enrique Lafuente Ferrari abría un ensayo sobre la labor censoria de Diego Velázquez: "La escasa posibilidad de que pueda hallarse, a estas alturas, algún fondo nuevo documental que nos ilustre sobre aspectos mal conocidos de la vida de Velázquez hace interesante cualquier aportación"31. En 2018, José Riello, al escribir sobre las biografías tempranas del pintor, notó que, en general, "son muy parcas en anécdotas" y que de las anécdotas que sí se conocen, pocas "revela[n] algo de su vida íntima"32. El testimonio de Pacheco no es tanto una anécdota sobre Velázquez como una anécdota donde Velázquez aparece brevemente como estrella invitada. No obstante, además de los temas ya señalados, esta aportación documental revela los estrechos vínculos que mantuvo Pacheco con su hija Juana y

\footnotetext{
25 García Gual, 1996: 47-60.

26 Pinto, 1576: 219 r.

27 Cervantes, 1998: 158.

28 Zemon Davis, 1987: 4.

29 Zemon Davis, 1987: 4.

30 Delpech, 1998: 7. Ver también Santana Paixão, 1999: 27-33.

31 Lafuente Ferrari, 1941: 55.

32 Riello, 2018: 1069-70.
} 
su yerno Diego Velázquez, residentes desde algunos años en la corte de Madrid, teniendo en cuenta que se conocen relativamente pocos ejemplos concretos que hablen de la relación entre Velázquez y su suegro en la segunda mitad de los $1620^{33}$. Demuestra también la sagacidad de Pacheco, ya que utilizó una ocasión que al parecer poco tenía que ver con temas áulicos para subrayar su relación con el pintor de cámara de Felipe IV. Los dos pintores-el suegro y el yerno, el maestro y el entonces aprendiz - continuarían apoyándose, revelando que su relación era de admiración, pero también, con toda probabilidad, de mutuo beneficio para ambos. De hecho, en 1626, muerto el pintor real Santiago Morán, Velázquez solicitó - sin éxito-la plaza para Pacheco ${ }^{34}$, mientras que unos años más tarde Pacheco alabaría a Velázquez en la lisonjera biografía de su yerno en El arte de la pintura ${ }^{35}$.

Es de esperar que investigadores futuros examinen el círculo de Pacheco, comparando el listado de los testigos llamados a dar testimonio sobre los prodigios modernos del santo rey Fernando III con los círculos alumbradistas conocidos de Sevilla en estos años, en particular la Congregación de la Granada, con la que tenían vinculación tanto Juan Martínez Montañés como Bernardo de Toro, el promotor de la causa fernandina en Roma ${ }^{36}$. Este enfoque abriría nuevas posibilidades para situar el testimonio de Pacheco dentro de su contexto social y religioso. Por ahora su declaración nos ayuda a profundizar nuestro conocimiento sobre la materialidad, estimación, temprana fama y biografía de uno de los objetos más llamativos del arte español y de la cultura intelectual de la temprana Edad Moderna.

\section{Apéndice}

\section{ASV Congr. Riti, Processus 1098, ff. 52 r-53 v.}

"En esta caussa para las ynformaciones sumarias de la vida, virtudes y milagros de el siervo de Dios señor Rey Don Fernando/ [en el margen: Fran. ${ }^{\text {co }}$ Pacheco de 63 anos] pressento por testigo al señor Fran. ${ }^{\text {co }}$ Pacheco comissario y ministro de el sancto officio para la vista y examen de las pinturas/ de las ymagenes nuevas del qual el dho señor juez tomo y recivio juramento tocando con las manos/ un libro de los sanctos evangelios y el susodho lo hizo y juro y prometio de dezir verdad de lo que supiere $\mathrm{Y}$ le fuere pre/guntado en esta dha causa dixo ser de hedad de sesenta y tres años, y que por ninguna via es ynteresado en esta causa, y si/endo preguntado por las Preguntas de el ynterrogatorio para en que fue pressentado dixo $=[\ldots]$ A la sesenta y seis y siete, hasta la setenta y una responde este testigo que es publica voz/ y fama de tiempo ynmemorial que a hecho y haze el bien aventurado Rey, y Dios por su yntercesion, ynume/rables milagros de los quales por mayor hazen memoria muchas historias authenticas, y que en particular/ a leydo muchos que se escriven en el flos sanctorum y vida deste sancto entre las vidas y milagros de otros/muchos recibidos en la yglessia por tales, y que assimismo a leydo, y sabe de otros muchos milagros mas mo/ dernos que en estos dias an sucedido, y sabe y oye dezir no cesa nuestro señor de honrrar a este su siervo/ con ottros muchos admirables casos en varias, y diversas materias como en salud, y enfermos desafuciados/ pero con mucha mas frequencia y opinion en materia de hallar cossas perdidas, o hurtadas, y que en par/ [en el margen: ojo] ticular a el le passo el casso siguiente $=$ que teniendo un libro de retratos de Varones ynsignes que era/ trabaxo suyo de mas de treynta años, y que lo estimava en mill ducados, el qual libro se lo hurtaron/ con otros muchos papeles y libros de la misma curiossidad, y facultad, y aviendolo echado menos, $\mathrm{y} /$ recibido singular pena por una tan gran perdida, de que le davan el pesame señores y amigos/ no solamente en esta ciudad, sino fuera de ella, un amigo devoto de el sancto Rey Don fernando le acon/ sexo mandase luego dezir una missa al sancto Rey, y este testigo con mucha confianza dio, y ymbio/ luego la limosna para que se digesse una missa, la qual se dixo luego a devocion de el sancto Rey/ a su sepulcro, y aunque hizo ottras diligencias y devociones le pareze q la de la misa de el sancto Rey/ fue la primera, y en la que siempre tuvo Particular confianza de hallar el hurto, y quisso nuestro/ señor que aviendolo echa-

33 Por ejemplo, el 3 de agosto de 1627 Velázquez y su esposa apoderaron a Pacheco para que este pueda vender sus propiedades en Sevilla: Corpus Velazqueño. Vol. I, 2000: 64.

34 Corpus Velazqueño. Vol. I, 2000: 56. Ver también Gállego, 1988: 56.

35 Pacheco, 2001: 202-203.

${ }^{36}$ Quiles, 1999: 211. Wunder, 2017: 33-36. González Polvillo, 2009: 69-72. 
do menos a siete de septiembre de el año passado de seiscientos y Veynte y sie/te vino aparezer el libro antes de cumplido un mes que fue a quattro de el octubre siguiente dia de/ san Francisco en Madrid con otro modo y circunstancia maravillosa que fue el mismo mozo q lo/ avia hurtado llevarselo a vender y poner en las manos a una hija de este testigo que estava y esta/ en Madrid que se llama Doña Juana Pacheco casada con Dg. ${ }^{\circ}$ Velasquez pintor y ugier de ca/mara de su mag. ${ }^{d}$ los quales reconocieron ser prenda de su Padre, con lo qual lo aseguraron, y le dieron/ aviso del hallazgo por lo qual aun antes de aver venido a su mano este dho testigo con persuasion/ de aver hallado la dha prenda por yntercession de el sancto Rey fue luego a dar limosnas hazer de/cir una missa en hacimiento de gracias por el hallazgo, a el sancto Rey una y otra a nuestra señora/ y dentro de otro tiempo le vino el libro con persona ppria, y con otras particulares circunstancias que aviendo/ sido el libro de quadernos sueltos, y de retratos y dibuxos sueltos que se pudieran cada uno de por si/ vender vino todo entero sin faltar una hoja tan sola, y sin averse maltratado, y este testigo no hizo/ casso, ni sintio la perdida de los otros papeles y libros juntam ${ }^{\text {te }}$ le hurtaron por que lo demas no/ lo estimava sino solamente este libro, y assi solamente le vino el libro por el qual solo avia hecho/ su particular devocion, de lo qual tuvieron muchos otros assi de esta ciudad como fuera de ella, particular/ noticia de este milagroso succeso, y dadole el parabien de ello, como de cossa de tanta estima, y de que en/ españa avia tanta noticia.

$[\ldots]$

A la setenta y seis dize que todo lo que a las preguntas a respondido es cierto/, publico y notorio, y lo a siempre oydo dezir a sus padres y mayores, y estar escripto en historias antiguas, y modernas/ y que assi lo afirma so cargo de el juramento que tiene hecho. y lo firma, y tambien el dho señor juez [una adición entre líneas: "y s ${ }^{\text {do }}$ le leyd, [ilegible]] = licenz./ Don Francisco de Melgar $=$ Fran. ${ }^{\text {co }}$ Pacheco $=$ Antemi el licenz. ${ }^{\text {do }}$ Geronimo de Pareja Aranda Notario./ Antemi fran. ${ }^{\text {co }}$ Ortiz de Salcedo Notario = en la ciudad de sevilla en diez y nueve dias del mes de henero de mil/ y seiscientos y veynte y ocho años ante el dho señor don Fran. ${ }^{\text {co }}$ de Melgar canonigo de la sancta yglesia desta ciudad Juez comissario desta causa, y ante nos los dhos Notarios".

\section{ASV Congr. Riti, Processus 1098, ff. 162r-162v.}

"El dho señor Jurado felix escudero de espinosa procurador de esta dha/ causa $\mathrm{p}^{\text {ra }}$ la dha ynformacion, pressento por testigo a Juan Martinez Monta/ñes natural de Alcala la real y vezino desta ciudad de quarenta a/ños a esta parte, y que es maestro del Arte de scultura y arquitectura, del/ qual se recibio juramento [...] y dixo ser de edad de mas de cinquenta y ocho años [...]

Y que abra de tres/ a quatro meses poco mas o menos a lo q se quiere acordar, que haviendose hurtado a Fran. ${ }^{\text {co } / P a c h e c o ~ p i n t o r ~ i n s i g n e ~ d e s t a ~ C i u d a d, ~ u n ~ l i b r o ~ d e ~ r e t r a t o s ~ d e ~ d i b u j o s ~ d e ~ p e r s o n a s ~ i n / s i g n e s, ~ y ~}$ varones ylustres de todo genero, de cosas q tenia hecho, y oy le va continuando/, q valia en el estado q se lo hurtaron mill ducados aviendo hecho muchas di/ligencias humanas para buscarle, y hecho dezir algunas misas a las animas/ de purgatorio segun dixo a este testigo, y con la devocion q como d[icho] es tiene al dho $\mathrm{s}^{\text {to }}$ rey don fer ${ }^{\text {do }} /$ le dixo, $\mathrm{q}$ le hiciese dezir una missa encomendandose, q Pareciese el dho li/bro, y el susodho la hizo dezir, y esta fue la ultima diligencia q hizo, y fue/ Dios servido q parecio en madrid el dho Libro, sin falta ninguna del".

\section{BIBLIOGRAFÍA}

Bassegoda i Hugas, Bonaventura (1991): "Cuestiones de iconografía en el Libro de retratos de Francisco Pacheco". En: Cuadernos de Arte e Iconografia, 7, pp. 186-196.

Bassegoda, Bonaventura (2000-2001): "El Libro de retratos de Pacheco y la verdadera efigie de don Diego Hurtado de Mendoza". En: Locus Amoenus, 5, pp. 205-216.

Bassegoda, Bonaventura (2012): “Reseña de Marta P. Cacho Casal, Francisco Pacheco y su Libro de retratos”. En: Goya, 339 , pp. 178-180.

Bassegoda, Bonaventura (2018): "Los retratos de los creadores literarios españoles del siglo de oro”. En Núñez Rivera, Valentín y Raúl Díaz Rosales (coordinadores), Vidas en papel: escrituras biográficas en la Edad Moderna. Huelva: Etiópicas. Revista de letras renacentistas, pp. 281-317.

Cacho Casal, Marta P. (2011): Francisco Pacheco y su Libro de Retratos. Sevilla: Fundación Focus-Abengoa, Madrid: Marcial Pons.

Cervantes, Miguel de (1998): El Ingenioso Hidalgo Don Quijote de la Mancha I, 19a edición, John Jay Allen (editor). Madrid: Cátedra, S. A.

Delpech, François (1998): "El hallazgo del escrito oculto en la literatura española del Siglo de Oro: elementos para una mitología del Libro”. En: Revista de dialectología y tradiciones populares, 53, 1, pp. 5-38. 
Fernández López, José (2002): Problemas iconográficos de la pintura barroca sevillana del siglo XVII, 2a edición. Sevi1la: Universidad de Sevilla.

Gállego, Julián (1988): Velázquez. Barcelona: Anthropos.

Gámez Martín, José (2005): “El sol es tu vestido. 'La Cieguecita’ de Martínez Montañés y la devoción concepcionista en Sevilla”. En: Francisco Javier Campos y Fernández de Sevilla (coordinador), La Inmaculada Concepción en España: religiosidad, historia y arte. Actas del simposium, San Lorenzo de El Escorial, 1-4 de septiembre de 2005, San Lorenzo de El Escorial: Estudios Escurialenses, t. 2, pp. 989-1005.

García Gual, Carlos (1996): "Un truco de la ficción histórica: el manuscrito reencontrado". En: 1616: Anuario de la Sociedad Española de Literatura General y Comparada, 10, pp. 47-60.

González Gómez, Juan Miguel (1995): “Escultura”. En: Teodoro Falcón Márquez (coordinador), Exposición Universitas Hispalensis: patrimonio de la Universidad de Sevilla, Sevilla: Universidad de Sevilla; Fundación El Monte.

González Polvillo, Antonio (2009): 'La Congregación de la Granada, el Inmaculismo sevillano y los retratos realizados por Francisco Pacheco de tres de sus principales protagonistas: Miguel Cid, Bernardo de Toro y Mateo Vázquez de Leca". En: Atrio, 15-16, pp. 47-72.

Lafuente Ferrari, Enrique (1941): "La inspección de los retratos reales en el siglo XVII (con un autógrafo de Velázquez)". En: Correo erudito, 2, pp. 55-58.

Meissen, Randall (2019): "Francisco Pacheco's Book of True Portraits: Humanism, Art, and the Practice of 'Visual History"”. En: Representations, 145, pp. 32-54

Navarrete Prieto, Benito (2016): "Un nuevo dibujo de Francisco Pacheco para su Libro de retratos: la efigie de Pablo de Céspedes en los Uffizi”. En: Archivo Español de Arte, 89, 353, pp. 77-84.

Pacheco, Francisco (2001): El arte de la pintura. Bonaventura Bassegoda i Hugas (editor), Madrid: Cátedra, S. A.

Pinto, Héctor (1576): Segunda parte de los dialogos de la imagen de la vida Christiana. Salamanca: Gaspar de Portonariis.

Pita Andrade, José Manuel (coordinador) y Ángel Aterido Fernández (editor) (2000): Corpus velazqueño. Documentos y textos, 2 vols. Madrid: Ministerio de Educación, Cultura y Deporte.

Quiles, Fernando (1999): "En los cimientos de la Iglesia sevillana: Fernando III, rey y santo". En: Boletín del Museo e Instituto 'Camón Aznar', 75-76, pp. 203-249.

Riello, José (2018): "Las siete vidas de Velázquez (y la penúltima interpretación de Las meninas)”. En: Alejandro Cañestro Donoso (coordinador), Scripta artium in honorem Prof. José Manuel Cruz Valdovinos, Alicante: Universidad de Alicante, pp. 1069-1090.

Salazar, Concepción (1928): "El testamento de Francisco Pacheco”. En: Archivo Español de Arte, 4, pp. 155-160.

Santana Paixão, Rosario (1999): "Mémoire et idéal historique: l'imaginaire des sources dans les livres de chevalerie ibériques au début du XVIe siécle". En: Jan Herman, Fernand Hallyn y Kris Peeters (coordinadores), Le topos du manuscrit trouvé. Actes du colloque international, Louvain-Gand, 22-23-24 mai 1997, Louvain-Paris: Éditions Peeters, pp. 27-33.

Wunder, Amanda (2001): "Murillo and the Canonisation Case of San Fernando, 1649-52". En: The Burlington Magazine, 143,1184 , pp. $670-675$.

Wunder, Amanda (2017): Baroque Seville: Sacred Art in a Century of Crisis. University Park: The Pennsylvania State University Press.

Zemon Davis, Natalie (1987): Fiction in the Archives: Pardon Tales and Their Tellers in Sixteenth-Century France. Stanford: Stanford University Press.

Fecha de recepción: 21-IV-2020

Fecha de aceptación: 24-VII-2020 